Illinois State University

ISU ReD: Research and eData

Theses and Dissertations

3-18-2014

\title{
Comparison Of Body Composition Techniques In Determining Body Fat Percentages In College Age Students
}

Jillian Louise Barnas

Illinois State University, jill.barnas@gmail.com

Follow this and additional works at: https://ir.library.illinoisstate.edu/etd

Part of the Kinesiology Commons

\section{Recommended Citation}

Barnas, Jillian Louise, "Comparison Of Body Composition Techniques In Determining Body Fat Percentages In College Age Students" (2014). Theses and Dissertations. 166.

https://ir.library.illinoisstate.edu/etd/166

This Thesis is brought to you for free and open access by ISU ReD: Research and eData. It has been accepted for inclusion in Theses and Dissertations by an authorized administrator of ISU ReD: Research and eData. For more information, please contact ISUReD@ilstu.edu. 


\title{
COMPARISON OF BODY COMPOSITION TECHNIQUES IN DETERMINING BODY FAT PERCENTAGES OF COLLEGE AGE STUDENTS
}

\author{
Jillian L. Barnas
}

47 Pages

May 2014

While the use of body composition analyzers can become a critical tool in breaking the continual weight loss/weight gain cycle in Americans, the accuracy of these analyzers at measuring body composition remains in question. PURPOSE: The purpose of this study was to determine the effectiveness of various body composition techniques at determining body fat percentages $(\% \mathrm{BF})$. METHODS: Sixty males (mean \pm SD) [age: $21.3 \pm 1.7$ yr., height: $178.1 \pm 7.2 \mathrm{~cm}$., mass: $81.9 \pm 12.6 \mathrm{~kg}$., body fat $\%: 14.6 \pm 7.5$ \%] and thirty-nine females [age: $20.5 \pm 0.9$ yr., height: $166.0 \pm 7.7 \mathrm{~cm} .$, mass: $63.5 \pm$ $11.6 \mathrm{~kg}$., body fat \%: $26.6 \pm 6.7 \%$ ] from a moderately sized, midwestern university participated in the study. Height and weight were obtained followed by six different body composition assessment techniques: Underwater Weighing with predicted residual volume (UWW-PredRV), Underwater Weighing with estimated residual volume (UWWForcedVC), Air Displacement Plethysmography (ADP), Bioelectrical Impedance (BIA) using Tanita analyzer (Tanita), BIA using Omron lower body analyzer (OmronLB), and BIA using Omron lower body/upper body analyzer (OmronLBUB). RESULTS: Twoway ANOVA with repeated measures detected significant differences $(p<0.05)$ in the body fat percentage with post hoc-comparisons revealing significant differences among 
UWW-ForcedVC (17.7 \pm 7.0$)$, OmronLB (23.9 \pm 5.5$)$, and OmronLBUB $(20.6 \pm 5.7)$ as compared to ADP-PredLV (14.6 \pm 7.5$)$ for males. Statistically significant differences $(\mathrm{p}<0.05)$ were detected by the ANOVA with post hoc-comparisons among Tanita $(24.4 \pm$ 7.6), OmronLB (31.6 \pm 5.4$)$, and OmronLBUB $(31.0 \pm 6.7)$ as compared to ADPPredLV (26.6 \pm 7.0$)$ for females. CONCLUSIONS: Although some methods had a strong correlation to ADP (PredLV), significant differences were detected between the techniques. Therefore, some techniques should be used cautiously since they may yield higher than expected results and more investigation needs to be completed on the validity of consumer-grade BIA assessment techniques. 
COMPARISON OF BODY COMPOSITION TECHNIQUES IN DETERMINING

BODY FAT PERCENTAGES OF COLLEGE AGE STUDENTS

\author{
JILLIAN L. BARNAS
}

A Thesis Submitted in Partial Fulfillment of the Requirements for the Degree of

MASTER OF SCIENCE

School of Kinesiology and Recreation

ILLINOIS STATE UNIVERSITY 
COMPARISON OF BODY COMPOSITION TECHNIQUES IN DETERMINING

BODY FAT PERCENTAGES OF COLLEGE AGE STUDENTS

JILLIAN L. BARNAS

COMMITTEE MEMBERS:

Dale D. Brown, Chair

Kelly R. Laurson

David Q. Thomas 


\section{ACKNOWLEDGEMENTS}

I wish to thank and recognize committee members Dr. Dale Brown, Dr. Kelly Laurson, and Dr. David Thomas for their contributions to the achievement of this research. I would like to express my gratitude for their patient guidance, encouragement, and useful critiques of this work. I would like to thank Dr. Dale Brown for his advice and assistance in keeping my progress on schedule. I would like to express gratitude to Dr. David Thomas for his valuable and constructive suggestions during the planning and development of this research. I would like to extend thanks to Dr. Kelly Laurson for his assistance in analyzing the data. Finally, I wish to thank my parents for their support and encouragement throughout my study.

J.L.B. 


\section{CONTENTS}

Page

ACKNOWLEDGEMENTS

$\begin{array}{ll}\text { CONTENTS } & \text { ii }\end{array}$

TABLES

FIGURES iv

CHAPTER

I. COMPARISON OF BODY COMPOSITION TECHNQIUES IN DETERMINING BODY FAT PERCENTAGE OF COLLEGE AGE STUDENTS

Introduction $\quad 1$

Methods $\quad 5$

Results $\quad 8$

Discussion $\quad 10$

Conclusion $\quad 14$

References 16

Tables $\quad 19$

Figures $\quad 21$

II. EXTENDED LITERATURE REVIEW

Introduction $\quad 24$

Body Fat Analysis $\quad 26$

Body Fat Assessment Techniques $\quad 27$

Body Fat Assessment Techniques Ability to Assess Body Fat Percentage 30

$\begin{array}{ll}\text { Summary } & 44\end{array}$

References $\quad 45$ 


\section{TABLES}

$\begin{array}{lll}\text { Table Page } & \end{array}$

1. Characteristics of Subjects 19

2. Mean Comparison of Body Composition Techniques 20 


\section{FIGURES}

Figure $\quad$ Page

1a. Mean Percent Body Fat of Males Assessed by

Criterion Reference (ADP) Compared to Different

Body Composition Techniques.

1b. Mean Percent Body Fat of Females Assessed by

Criterion Reference (ADP) Compared to Different

Body Composition Techniques.

2. Correlation and Regression Analyses of Body

Composition Techniques Significantly Different from

Criterion Reference (ADP) for Males.

3. Correlation and Regression Analyses of Body

Composition Techniques Significantly Different from

Criterion Reference (ADP) for Females. 


\section{CHAPTER 1}

\section{COMPARISON OF BODY COMPOSITION TECHNIQUES IN DETERMINING BODY FAT PERCENTAGE OF COLLEGE AGE STUDENTS}

\section{Introduction}

According to the Centers for Disease Control and Prevention, nearly $64 \%$ of Americans are classified as overweight or obese (5). The ability to accurately measure body fat is critical because of the established association of excess body fat and a variety of diseases such as diabetes mellitus, hypertension, cardiovascular disease, and hyperlipidemia $(2,17,20,22)$. Many researchers contemplate the use of body mass index (BMI) as a means of assessing overweight and obesity in the general population due to its feasibility. An individual's BMI is the product of their mass in kilograms (kg) divided by height in meters, squared $\left(\mathrm{m}^{2}\right)$.

BMI relies on cut off levels based on associations with mortality and morbidity in large population surveys that have been recommended as guidelines to determine healthy, desirable weights. Research has indicated that BMI may be a useful tool in assessing the general population $(13,15)$. However, other studies have demonstrated the need for more measures other than BMI when assessing individuals, especially athletes whose sport requires them to be larger $(4,17)$. BMI has been criticized because it does not differentiate between fat, muscle, bone, water, or vital organs $(4,17)$. Therefore, an individual with 
high fat-free mass (FFM) relative to stature may have a high BMI value but may not be obese (26).

Given the questions surrounding BMI, the need for body composition assessment technology has been in high demand. In the past, there were relatively few options available for the measurement of body composition such as bioelectrical impedance (BIA), underwater weighing (UWW), air displacement plethysmography (ADP), and Dual-energy X-ray absorptiometry (DXA) (2-4,7-22,24-26). Most of the older technologies were expensive, lacked portability, and required expertise to operate. These older technologies are still considered criterion methods of assessing body composition. Inconveniently, UWW and ADP are not readily available to the general population. Underwater weighing requires the use of technical expertise to ensure the validity of each test using repeated submersion with a maximal exhalation, which can lead to client discomfort $(2,10,25)$. Air displacement plethysmography utilizing the BOD POD ${ }^{\circledR}$ can be viewed as advantageous due to the fact that it requires less technical skill than UWW and uses air instead of water to calculate density which provides the subject with a more comfortable testing environment $(2,8-10,16,17,19,25)$. Some studies indicate that there is no significant difference between ADP and UWW $(2,9)$ whereas other studies indicate there is a difference between the two methodologies (25).

With the increasing demand to assess body composition, recent technological advances have resulted in a wide variety of types, models, and brands of body composition analyzers $(1-3,8,13,19-21)$. A variety of consumer grade devices targeted at the public claim to estimate $\% \mathrm{BF}$ accurately through bioelectrical impedance. There are numerous studies investigating body composition techniques that are available to 
consumers and it has recently been questioned whether the consumer grade devices utilizing bioelectrical impedance analysis (BIA) may be accurately used for determining body composition $(1,2,7,12,18-20,24)$.

BIA is based on the underlying principle that resistance or impedance to the flow of an electrical current through the body is dependent on three variables: length of the conductive path, volume of the conductive path, and the resistivity of the conductive material (18). Omron ${ }^{\circledR}$ and Tanita ${ }^{\circledR}$ analyzers have become sought-after products by consumers for their claimed precision and accuracy $(1,2,7,12,18-20,24)$. Numerous studies have been conducted using methodologies of comparing a variety of consumer grade devices to criterion references: ADP, UWW, and DXA.

Results from the literature consistently show that the inexpensive consumer products significantly overestimated body fat percentage $(\% \mathrm{BF})$ in males and females, but to a greater degree in females $(1,19-21,24)$. Although the products differ significantly from the established criterion references, it is suggested that the products can be used as tools to gain a general idea of body composition for males. This notion cannot be applied to females due to the greater degree of overestimation (18-20). In cases where an accurate measurement of $\% \mathrm{BF}$ is crucial, using a more established method than the consumer grade products is recommended. However, some studies suggest that the consumer grade products do not differ significantly from established criterion references and can be used as field assessment tools to assess body composition $(3,7,12)$. Research indicates inconsistent findings and more studies are needed to investigate the newly developed consumer products validity and reliability. 
The purpose of this study was to determine the effectiveness of various body composition techniques for the determination body fat percentage $(\% \mathrm{BF})$. More specifically, this study will compare the validity of six different body composition techniques in determining body fat and fat free mass for males and females. Air displacement plethysmography (ADP) was used as the criterion reference in the body composition technique comparisons. While measured lung volumes can be obtained with ADP, research indicates there is no significant difference between the body composition results in ADP when using measured lung volume as compared to predicted lung volume $(8,11)$. As a result, air displacement plethysmography with a predicted lung volume was then used as the criterion reference due to its established accuracy to the scientific community, accessibility, and to its lack of discomfort it creates during the assessment. Underwater weighing was selected for comparison due to the conflicting research as to whether the two methodologies are significantly different $(2,9,25)$. Underwater weighing in this study used a predicted residual long volume and a measured residual lung volume calculated from a force vital capacity. Two consumer grade BIA scales were used in this study: Omron HBF-206IT, Omron HBF-514 (Omron Healthcare, INC, Bannockburn, IL) in conjunction with the Tanita TBF-300A (Tanita Corporation of America, Arlington Heights, IL). It is hypothesized that there will be no significant differences between ADP and UWW for $\mathrm{Db}$ and \%fat however, there will be significant differences between the various BIA scales compared to ADP between males and females. 


\section{Methods}

Participants: Sixty males and 39 females $(n=99)$ volunteered from a moderately sized, midwestern university. The physical characteristics of the participants are presented in Table 1. Participants gave written informed consent for their involvement in this study using forms that had been reviewed and approved by the Institutional Review Board.

Procedures: Prior to all testing, participants were instructed to report to the laboratory having fasted 4 hours, avoided caffeine for 12 hours, avoided alcohol for 48 hours, and avoided exercising 6 hours. Participants were also instructed to void their bladder and bowels within 30-minutes prior to testing. Due to the relevancy of hair and clothing on the ADP and UWW measurements, the participants wore a swimsuit or spandex shorts with a sports bra for females, and a swim cap (ADP) to eliminate excess air pockets.

Height was assessed using a standard scale and weight was obtaining using the BOD POD ${ }^{\circledR}$ calibrated scale. Before any of the assessments, participants completed pulmonary function testing to assess their forced vital capacity (FVC) with residual volume subsequently calculated from the FVC measure. This was calculated by multiplying the FVC by 0.24 for males and 0.28 for females. Each subject had their body composition (body fat and fat free mass) analyzed using six commonly used laboratory techniques. Body mass index was calculated and bioelectrical impedance was performed as initial assessments. BOD POD ${ }^{\circledR}$ analysis followed with a predicted lung volume. Lastly, each subject was underwater weighed using predicted and measured lung 
volumes.

Body Mass Index Measurement: Participants had their height and weight measured. Body mass index was calculated using the individual's mass in kilograms divided by their height in meters squared.

Bioelectrical Impedance Analysis: Bioelectrical impedance measurements were made using impedance systems by two different companies; Omron (Omron Healthcare, INC, Bannockburn, IL) and Tanita (Tanita Corporation of America, Arlington Heights, IL). The impedance systems that were used are the Omron HBF-206IT, Omron HBF-514, and Tanita TBF-300A. Bioelectrical impedance analysis is a relatively quick and simple method for estimating $\% \mathrm{BF}$. Its function is dependent upon the measurement of resistance of the body's tissues. Each impedance system assessed weight and body fat percentage through assessment of the lower body or both upper and lower body. Each impedance system asked questions of height, sex, and age. The Tanita Scale took into account the subject's athletic status. Athlete was selected for the individuals who met the criteria as per manufacturer's instructions: participating in vigorous activity at least 10 hours per week for 6 months and having a resting heart rate of 60 beats per minute. Participants placed their feet and/or hands on the electrodes and were asked to remain still until the measurement was completed.

Residual Volume: Vital capacity was obtained using the Vitalograph PFT II Plus Spirometer (Vitalograph Inc., Kansas City, MO). Following a maximal inspiration, participants were instructed to forcefully and expediently expel as much air as possible when using the spirometer. Three maximal forced expiratory maneuvers were 
performed, and the best-forced expiratory flow was recorded and subsequently used for data analysis. Residual volume (RV) was estimated as a percentage of the measured vital capacity by means of multiplying the volume by 0.24 for males and 0.28 for females. Estimated residual volume was used in conjunction with UWW for the determination of body composition.

Air Displacement Plethysmography: Before entering the BOD POD ${ }^{\circledR}$, it was calibrated according to manufacturer's instructions (Life Measurement Inc., Concord, CA). Participants were tested wearing a swimsuit or spandex shorts and sports bra for females, and a swim cap to compress their hair. Before entering the chamber, participants were weighed on a calibrated digital scale. The subject then entered the apparatus for testing. The measurement included a predicted lung volume instead of a measured lung volume. Research indicates there is no significant difference between ADP with a measured lung volume and a predicted lung volume $(8,11)$. Once two consistent measures of body volume were achieved, density was determined using BOD POD ${ }^{\circledR}$ calculated body volume and mass. Density was used to calculate percent body fat using the Siri equation (23).

Underwater Weighing: Underwater weighing was assessed utilizing the body density measuring system developed by EXERTECH ${ }^{(E X E R T E C H ~ B o d y ~}$ Densitometry System, Dresbach, MN). Subjects were required to wear spandex shorts and/or sports bra for the assessment. Each subject was weighed while seated on a chair attached to a four-point electronic load cell scale. The subject is instructed to expel as much air as possible from his or her lungs during complete under water submersion. It 
was at this point that the underwater weight of the subject was acquired. The heaviest underwater weight measurement and the estimated RV or measured RV was then used in the determination of body density. The body density value was entered into the Siri equation (23) to calculate percent body fat.

Statistical Analysis. Data were analyzed using SPSS 20 for windows (SPSS Inc., Chicago, IL) and Microsoft Excel for windows (Microsoft Corp., Seattle, WA). Values are expressed as means $\pm \mathrm{SD}$. A $2 \times 2$ (instrument $\mathrm{x}$ gender) factorial ANOVA was performed to detect significant differences in $\%$ BF among the six testing methods (ADP, UWW-PredRV, UWW-ForcedVC, Omron LB, Omron LBUB, and Tanita) across sex. An alpha level of 0.05 was used for significance testing. Pearson's Product Moment correlation was computed to examine the relationship between the $\% \mathrm{BF}$ estimates from the instruments that were significantly different from ADP. Since a high correlation does not necessarily imply agreement, linear regression analyses were performed with \% BF assessed from ADP as the dependent variable to provide indication of an over/under estimation between the measures.

\section{Results}

The characteristics of the participants are presented in Table 1. The subjects consisted of 60 males and 39 females from a moderately sized, midwestern university. Mean percentage of body fat for each analysis collapsed across sex is included in Table 2. The mean percentage of body fat compared between males and females for each analysis is displayed in Figure 1a, 1b, and included in Table 2.

Two-way ANOVAs with repeated measures detected a significant interaction 
between assessment technique and gender. Significant differences $(\mathrm{p}<0.05)$ were detected in the body fat percentages with post hoc-comparisons revealing no differences in UWWPredRV $(16.1 \pm 6.8)$ and Tanita $(15.6 \pm 7.6)$ as compared to ADP-PredLV $(14.6 \pm 7.5)$ for males, whereas significant differences $(\mathrm{p}<0.05)$ were detected among UWWForcedVC (17.7 \pm 7.0$)$, OmronLB $(23.9 \pm 5.5)$, and OmronUBLB $(20.6 \pm 5.7)$ as compared to ADP-PredLV $(14.6 \pm 7.5)$ (Figure 1a). Significant differences $(\mathrm{p}<0.05)$ were detected in the body fat percentages with post hoc-comparisons revealing no differences in UWW-PredRV $(25.7 \pm 8.9)$ and UWW-ForcedVC $(27.4 \pm 8.6)$ as compared to ADP-PredLV (26.6 \pm 7.0$)$ for females, whereas significant differences $(\mathrm{p}<0.05)$ were detected among BIA-Tanita $(24.4 \pm 7.6)$, OmronLB $(31.6 \pm 5.4)$, and OmronUBLB (31.0 \pm 6.7$)$ as compared to ADP-PredLV (26.6 \pm 7.0$)$ (Figure 1b). Based on the results of the two-way ANOVA, Pearson's Product Moment correlation and regression analyses for those techniques that were significantly different from the criterion method (ADP) between males and females were completed to examine the relationship while providing an indication of over or under estimation of $\% \mathrm{BF}$. Strong correlation coefficients were seen between ADP and Tanita $(r=0.84)$ (Figure 3a) and Omron LBUB $(r=0.79)$ (Figure $3 b)$ for females and Omron LBUB for males $(r=$ 0.79) (Figure 2b). Moderate correlation coefficients were seen between ADP and UWW (ForcedVC) for males $(\mathrm{r}=0.67)$ (Figure 2a) and OmronLB $(\mathrm{r}=0.68)$ (Figure 3c) for females. A low correlation coefficient was seen between ADP and Omron LB $(r=0.47)$ (Figure 2c) for males. 


\section{Discussion}

This investigation evaluated the effectiveness of various body composition techniques for the determination of body fat percentage in college age students. The most significant finding of this study is the Omron ${ }^{\circledR}$ consumer-grade scales, both OmronLB and OmronLBUB, overestimate $\% \mathrm{BF}$ approximately $5-9 \%$ compared to the criterion reference for both males and females. The results of this study are important because a variance of 5-9\% body fat could mean the classification of a healthy individual versus one who is at risk for health complications. To make this data applicable to the general population, an overestimation of $\%$ BF may encourage an individual to lose weight when weight loss is not warranted. Due to the availability of the consumer-grade scales and the ability to test large amounts of people at one time, it is important that the results given from the assessment are accurate.

Two-way ANOVAs indicated an interaction effect between the body composition assessments and gender. For males, \%BF was approximately $6-9 \%$ higher than the criterion reference for OmronLBUB and OmronLB. For females, \%BF was approximately 5-6\% higher than the criterion reference for OmronLBUB and OmronLB. Additionally, there were no significant differences between the criterion reference and UWW-PredRV and Tanita in determining \%BF for males. There was a significant difference between UWW-VC and the criterion reference; however, those results are not practically significant since is it relatively accepted that the error of the measurement is $\pm 1-2 \%$ (8). Additionally, there were no significant differences between the criterion reference, UWW-PredRV and UWW-ForcedVC for females, but there were significant 
differences between the criterion reference and Tanita.

Even with the presence of significant differences between methods, the interest in practical application is still important. There may be individuals or companies that may wish to use a technique like BIA because it is inexpensive. The correlation and regression analyses give indication of the relationship of each assessment compared to the criterion method (Figure 2 and 3). Each regression plot has a line of identity to establish a perfect correlation $(\mathrm{r}=1.0)$ as well as their correlations to assess the techniques agreement. If the lines were parallel, it may be relatively easy to correct the assessment technique by adjusting up or down accordingly. In females, for example, the Tanita and criterion reference are almost parallel, indicating a small percent difference (Figure 3a). For males, the OmronLB compared to the criterion reference indicates a very poor relationship and may be more difficult to predict through a correction equation indicating that this assessment should not be used due to little accuracy to the criterion method (Figure 2c). While there are relatively strong relationships between the methods that were significantly different from the criterion reference, the use of technology should be used with caution.

The results of this investigation are consistent with previous findings in that the inexpensive consumer products significantly overestimated $\% \mathrm{BF}$ in males and females $(1,18-20,24)$. In this study, there are significant differences between the Omron ${ }^{\circledR}$ products and the analyzers in measuring the percent fat of females and males which supports the findings of previous investigations $(1,4,8,13,18-20)$. The investigations that indicate a significant difference in the consumer grade products ability to accurately 
assess body composition utilize various criterion references. This study is the first to utilize the Omron HBF-514 and HBF-206IT. Previous research indicates inconsistent findings and more studies are needed to investigate the newly developed consumer products validity and reliability. Pateyjohns et al. (2006) indicates a large bias and wide limit of agreement in consumer grade BIA products. Peterson et al. (2011) investigated consumer grade BIA devices and found that the various measures may highly correlate with the criterion references, but overestimated or underestimated individual $\% \mathrm{BF}$. Although the products differ significantly from the established criterion references, it is suggested that the products can be used as tools to gain a general idea of body composition for males $(1,18-20)$. This notion cannot be applied to females due to the greater degree of overestimation (18-20). However, the results of this study concluded a greater degree of overestimation in males when compared to females, which could be due to the differing sample sizes. In cases where an accurate measurement of $\% \mathrm{BF}$ is crucial, using a more established method, such as ADP or UWW would be warranted, rather than using a consumer grade product.

Some studies suggest that the consumer grade products do not differ significantly from established criterion references $(3,7,12)$ and can be used as field assessment tools to assess body composition. The established references have varied for each study using ADP, unerwater weighing, and DXA. Although the studies have indicated no significant differences between the measures, the consumer grade techniques have given higher readings of body fat percentages than the criterion references $(3,7,12)$. In all studies, the devices greatly, however not significantly, overestimated $\mathrm{BF} \%$ in women compared to 
men, which is the opposite of what was indicated in the results of this study. JenskySquires et al. (2008) indicated that the Omron ${ }^{\circledR}$ products are accurate devices for determining body composition in the general population except for young adults between 18-35 years old which was similar to the population used in this study. Bosy-Westphal et al. (2008) compared Omron ${ }^{\circledR}$ and Tanita ${ }^{\circledR}$ scales to DXA. The results demonstrated no differences between the measurements and the criterion reference, however, the results indicated that the Omron ${ }^{\circledR}$ scales were more accurate than the Tanita ${ }^{\circledR}$ which is contradictory to the results found in this study.

Another important aspect of this study involves the consideration of validity of the assessment techniques. The results of this study show that certain assessment techniques are not valid for both genders. It is relatively accepted that the error of measurement for ADP and UWW with a predicted lung volume is approximately $3 \%$ while a measured vital capacity is $\pm 1-2 \%$ (8). Research indicates there is no significant difference between ADP with a measured lung volume and a predicted lung volume $(8,11)$. However, BIA has an error of the measurement of approximately $\pm 3-5 \%(24)$. The results of this study are indicative that the Omron ${ }^{\circledR}$ scales are approximately 5-9\% off for both genders indicating that this is not a valid assessment technique for determining body composition. Furthermore, it should be noted that participants were not monitored to make sure pre-test instructions were followed; we relied subject-to-subject compliance. Although participants were questioned about their compliance with pre-test instructions, the participants may not have followed the instructions and could have affected the individual body composition result for each technique. However, it should be noted that 
studies monitoring subject compliance with pre-test instructions, found very little although significant differences in the validation of ADP and UWW (25). Assuming the measurement and analyzer error given the average body weight, the body composition result can change with the analyzer due to different density equations and the different manufacturing of the product.

\section{Conclusion}

The use of body composition analyzers can become a critical tool in breaking the continual weight loss/weight gain cycle seen in the lives of millions of Americans daily. An accurate assessment of body composition that is accessible in terms of price, ease of use, and availability has led to the production of consumer-grade products based off company-manufactured algorithms (19). With the products becoming more available in homes and in field-testing, it is important to ensure their accuracy. The data suggest that \%BF can be accurately estimated using various body composition techniques used in this study, however, gender should be considered when selecting an assessment technique. Some techniques should be used cautiously since they may yield higher than expected results. Although not assessed, assuming these analyzers have a consistent inaccuracy at measuring body composition, the devices may be useful in assessing relative changes across time rather than the results of a single, absolute measurement. This would be give helpful information to the general population about changes in their body composition when a criterion reference cannot be used. Furthermore, the reliability of these devices needs to be established and investigations need to be completed on consumer grade body composition assessment techniques before they can be deemed valid testing procedures 
for the general population. 


\section{References}

1. Beam, J. R., \& Szymanski, D. J. (2010). Validity of 2 Skinfold Calipers in Estimating Percent Body Fat of College-Aged Men and Women. Journal of Strength, 24(12), 3448-3456. doi:10.1519/JSC.0b013e3181bde1fe

2. Biaggi, R. R., Vollman, M. W., Nies, M. A., Brener, C. E., Flakoll, P. J., Levenhagen, D. K., Sun, M., Karabulut, Z., \& Chen, K. Y. (1999). Comparison of airdisplacement plethysmography with hydrostatic weighing and bioelectrical impedance analysis for the assessment of body composition in healthy adults. The American journal of clinical nutrition, 69(5), 898-903.

3. Bosy-Westphal, A., Later, W., Hitze, B., Sato, T., Kossel, E., Gluer, C.-C., Heller, M., \& Muller, M. J. (2008). Accuracy of bioelectrical impedance consumer devices for measurement of body composition in comparison to whole body magnetic resonance imaging and dual X-ray absorptiometry. Obesity facts, 1(6), 319-324. doi:10.1159/000176061

4. Buell, J.L., Calland, D., Hanks, F., Johnston, B., Pester, B., Sweeney, R., Thorne, R. (2008). Presence of Metabolic Syndrome in Football Linemen. Journal of Athletic Training, 43(6), 608-616.

5. Center for Disease Control [Internet]. Atlanta, GA. Healthy People 2010: Focus on Area 12 Heart Disease and Stroke. Available from http://www.cdc.gov/dhdsp/library/hp2030/objectives.

6. Dehghan, M., \& Merchant, A. T. (2008). Is bioelectrical impedance accurate for use in large epidemiological studies? Nutrition Journal, 7(1), 26. doi:10.1186/14752891-7-26

7. Demura, S., Sato, S., \& Kitabayashi, T. (2004). Percentage of Total Body Fat as Estimated by Three Automatic Bioelectrical Impedance Analyzers. Journal of Physiological Anthropology and Applied Human Science, 23(3), 93-99.

8. Fields, D. A., Goran, M. I., \& McCrory, M. A. (2002). Body-composition assessment via air-displacement plethysmography in adults and children: a review. The American Journal of Clinical Nutrition, 75(3), 453-467.

9. Gately, P. J., Radley, D., Cooke, C. B., Carroll, S., Oldroyd, B., Truscott, J. G., Coward, W.A., \& Wright, A. (2003). Comparison of body composition methods in overweight and obese children. Journal of Applied Physiology, 95(5), 20392046. doi:10.1152/japplphysiol.00377.2003 
10. Ginde, S. R., Geliebter, A., Rubiano, F., Silva, A. M., Wang, J., Heshka, S., \& Heymsfield, S. B. (2005). Air displacement plethysmography: validation in overweight and obese participants. Obesity research, 13(7), 1232-1237. doi:10.1038/oby.2005.146

11. Good, J.D., Brown, D.D., Dennis, K.K., \& Kravanya, K.A. (2008). Validity of Predicted Thoracic Gas Volumes in Determining Body Composition during Air Displacement Plethysmography in Collegiate Athletes. Medicine and Science in Sports and Exercise, 40(5): (abstract $\mathrm{t} \# 1666)$.

12. Jensky-Squires, N. E., Dieli-Conwright, C. M., Rossuello, A., Erceg, D. N., McCauley, S., \& Schroeder, E. T. (2008). Validity and reliability of body composition analyzers in children and adults. British Journal of Nutrition, 100(04), 859-865. doi:10.1017/S0007114508925460

13. Laurson, K.R., Eisenmann, J.C. (2007). Prevalence of Overweight Among High School Football Linemen. JAMA, 297(4), 363-364.

14. Loenneke, J. P., Wilson, J. M., Wray, M. E., Barnes, J. T., Kearney, M. L., \& Pujol, T. J. (2012). The Estimation of the Fat Free Mass Index in Athletes. Asian Journal of Sports Medicine, 3(3), 200-203.

15. Malina, R.M., Morano, P.J., Barron, M., Miller, J.S., Cumming, S.P., Kontos, A.P., Little, B.B. (2007). Overweight and Obesity among Youth Participants in American Football. The Journal of Pediatrics, 151, 378-382.

16. Noreen, E. E., \& Lemon, P. W. (2006). Reliability of air displacement plethysmography in a large, heterogeneous sample. Medicine and science in sports and exercise, 38(8), 1505.

17. Ode, J. J., Pivarnik, J. M., Reeves, M. J., \& Knous, J. L. (2007). Body mass index as a predictor of percent fat in college athletes and nonathletes. Medicine and science in sports and exercise, 39(3), 403.

18. Pateyjohns, I. R., Brinkworth, G. D., Buckley, J. D., Noakes, M., \& Clifton, P. M. (2006). Comparison of Three Bioelectrical Impedance Methods with DXA in Overweight and Obese Men. Obesity, 14(11), 2064-2070. doi:10.1038/oby.2006.241

19. Peterson, J., Repovich, W., \& Parascand, C. (2011). Accuracy of Consumer Grade Bioelectrical Impedance Analysis Devices Compared to Air Displacement Plethysmography. International Journal of Exercise Science, 4(3). Retrieved from http://digitalcommons.wku.edu/ijes/vol4/iss3/2 
20. Pribyl, M., Smith, J., \& Grimes, G. (2011). Accuracy of the Omron HBF-500 Body Composition Monitor in Male and Female College Students. International Journal of Exercise Science, 4(2). Retrieved from http://digitalcommons.wku.edu/ijes/vol4/iss2/2

21. Romero-Corral, A., Somers, V. K., Sierra-Johnson, J., Thomas, R. J., Bailey, K. R., Collazo-Clavell, M. L., Allison, T.G., Korinek, J., Batsis, J.A., \& Lopez-Jimenez, F. (2008). Accuracy of Body Mass Index to Diagnose Obesity In the US Adult Population. International journal of obesity (2005), 32(6), 959-966. doi:10.1038/ijo.2008.11

22. Steinberger, J., Jacobs, D. R., Raatz, S., Moran, A., Hong, C.-P., \& Sinaiko, A. R. (2005). Comparison of body fatness measurements by BMI and skinfolds vs dual energy X-ray absorptiometry and their relation to cardiovascular risk factors in adolescents. International journal of obesity (2005), 29(11), 1346-1352. doi:10.1038/sj.ijo.0803026

23. Siri, W.E. (1956) The gross composition of the body. Advanced Biomedical Physiology. 4:239-280.

24. Utter, A.C., Scott, J.R., Oppliger, R.A., Visich, P.S., Goss, F.L., Marks, B.1, Nieman, D.C., \& Smith, B.W. (2001). A comparison of leg-to-leg bioelectrical impedance and skinfolds in assessing body fat in collegiate wrestlers. Journal of strength and conditioning research / National Strength \& Conditioning Association, 15(2), $157-160$.

25. Wagner, D. R., Heyward, V. H., \& Gibson, A. L. (2000). Validation of air displacement plethysmography for assessing body composition. Medicine and science in sports and exercise, 32(7), 1339-1344.

26. Wellens, R. I., Roche, A. F., Khamis, H. J., Jackson, A. S., Pollock, M. L., \& Siervogel, R. M. (1996). Relationships Between the Body Mass Index and Body Composition. Obesity Research, 4(1), 35-44. doi:10.1002/j.15508528.1996.tb00510.x 
TABLE 1. Characteristics of Subjects

\begin{tabular}{lllll}
\hline Variable & $\begin{array}{l}\text { Combined }^{\mathrm{a}} \\
(\mathrm{n}=99)\end{array}$ & $\begin{array}{l}\text { Males }^{\mathrm{a}} \\
(\mathrm{n}=60)\end{array}$ & $\begin{array}{l}\text { Females }^{\mathrm{a}} \\
(\mathrm{n}=39)\end{array}$ & $\begin{array}{l}\text { Range } \\
(\mathrm{n}=99)\end{array}$ \\
\hline Age (years) & $21.0(1.5)$ & $21.3(1.7)$ & $20.5(0.9)$ & $19.0-30.0$ \\
Height $(\mathrm{cm})$ & $173.7(9.2)$ & $178.1(7.2)$ & $166.0(7.7)$ & $152.0-182.0$ \\
& & & & \\
Mass $(\mathrm{kg})$ & $74.6(15.2)$ & $81.9(12.6)$ & $63.5(11.6)$ & $43.7-111.0$ \\
\% Body Fat (ADP) & $19.4(9.4)$ & $14.6(7.5)$ & $26.6(6.7)$ & $5.2-43.4$ \\
& & & & \\
BMI (kg/m $\left.{ }^{2}\right)$ & $24.6(3.7)$ & $25.8(3.5)$ & $22.7(3.2)$ & $17.50-40.3$ \\
\hline
\end{tabular}

${ }^{\mathrm{a}}$ Values are means \pm standard deviation in parentheses 
TABLE 2. Mean Comparison of Body Composition Techniques

\begin{tabular}{llll}
\hline Testing Method & $\begin{array}{l}\text { Body Fat \% } \\
\text { Combined }^{\mathrm{a}} \\
(\mathrm{n}=99)\end{array}$ & $\begin{array}{l}\text { Body Fat \% } \\
\text { Males }^{\mathrm{a}}\end{array}$ & $\begin{array}{l}\text { Body Fat \% }_{\text {Females }}^{\mathrm{a}} \\
(\mathrm{n}=39)\end{array}$ \\
\hline ADP (PredLV) & $19.4(9.4)$ & $14.6(7.5)$ & $26.6(7.0)$ \\
Tanita & $19.1(7.9)$ & $15.6(5.8)$ & $24.4(7.6)^{\$}$ \\
UWW (PredRV) & $19.9(9.0)$ & $16.1(6.8)$ & $25.7(8.9)$ \\
UWW (ForcedVC) & $21.5(9.0)^{*}$ & $17.7(7.0)^{\wedge}$ & $27.4(8.6)$ \\
Omron LBUB & & & $31.0(6.7)^{\$}$ \\
Omron LB & $24.7(7.5)^{*}$ & $20.6(5.7)^{\wedge}$ & \\
\hline
\end{tabular}

${ }^{a}$ Values are means \pm standard deviation in parentheses

*Significantly different from ADP at $\mathrm{p}<0.05$

Significantly different from ADP for males at $p<0.05$

${ }^{\$}$ Significantly different from ADP for females at $\mathrm{p}<0.05$ 
FIGURE 1a. Mean Percent Body Fat of Males Assessed by Criterion Reference (ADP) Compared to Different Body Composition Techniques.

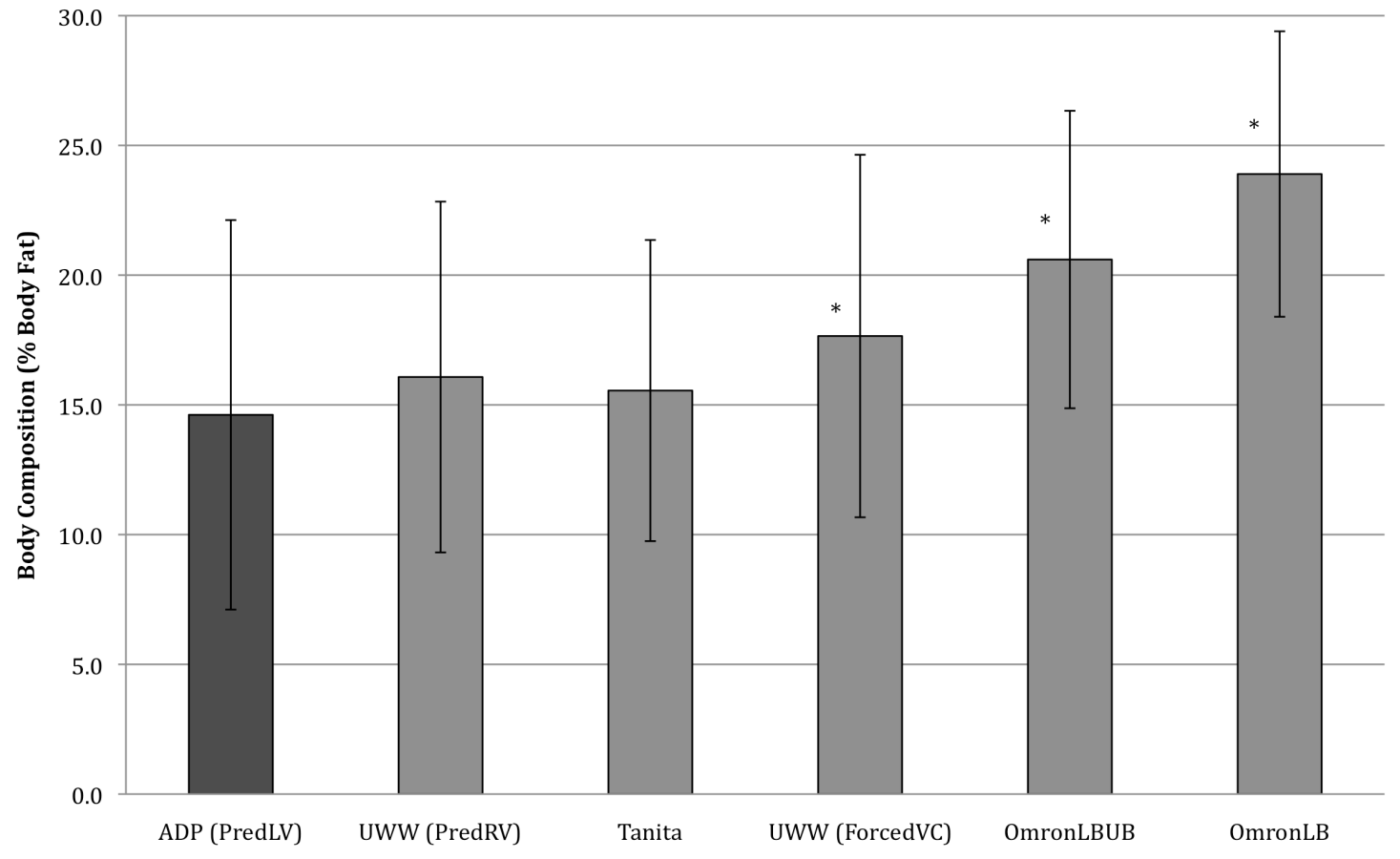

FIGURE 1b. Mean Percent Body Fat of Females Assessed by Criterion Reference (ADP) Compared to Different Body Composition Techniques.

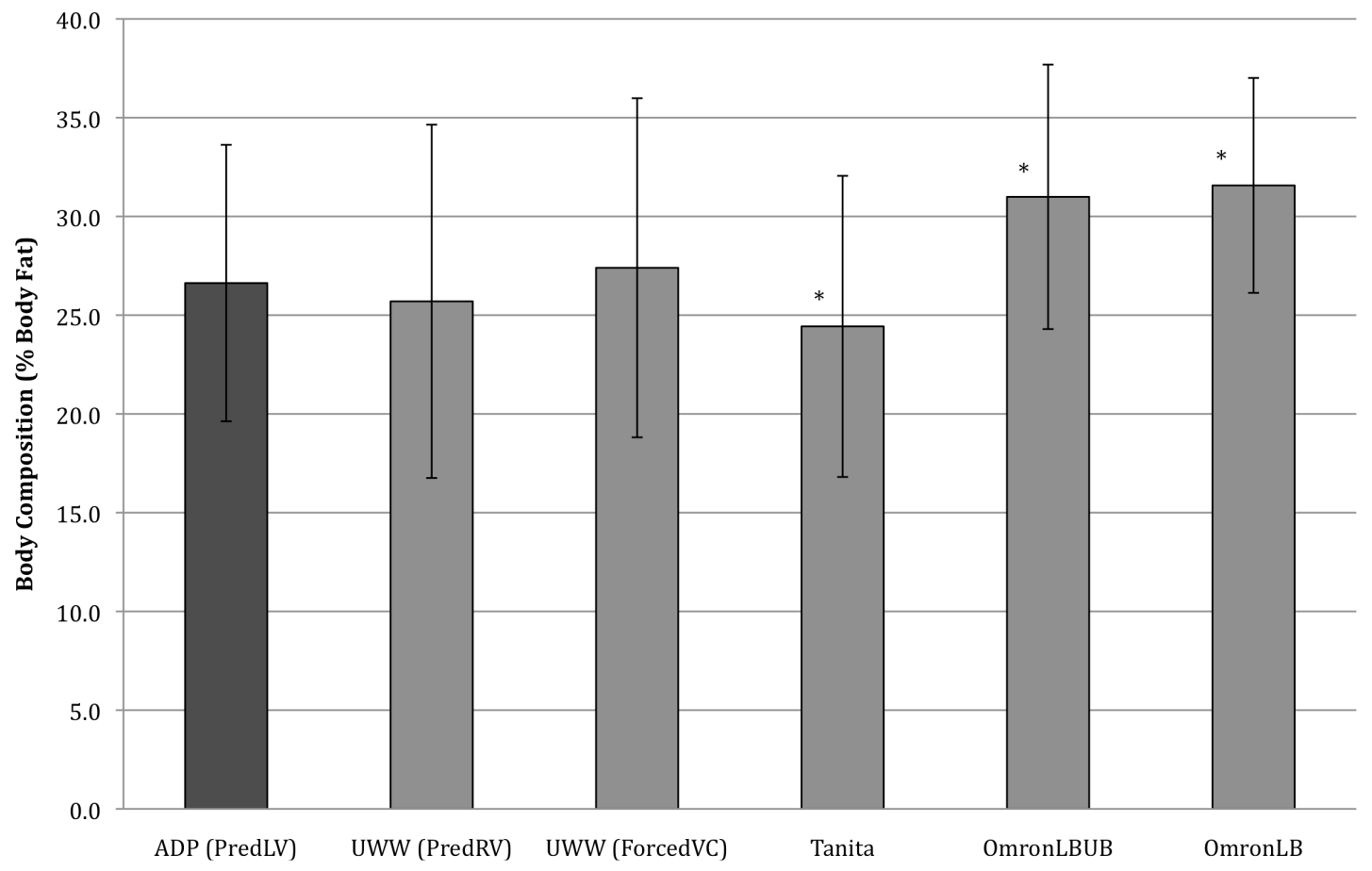

*Significantly different from ADP $(\mathrm{p}<0.05)$ 
FIGURE 2. Correlation and Regression Analyses of Body Composition Techniques Significantly Different from Criterion Reference (ADP) for Males.

a.

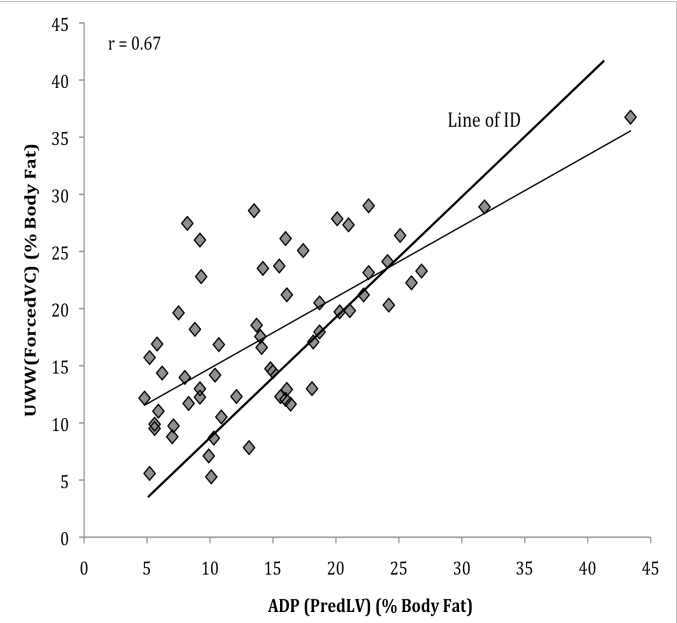

b.

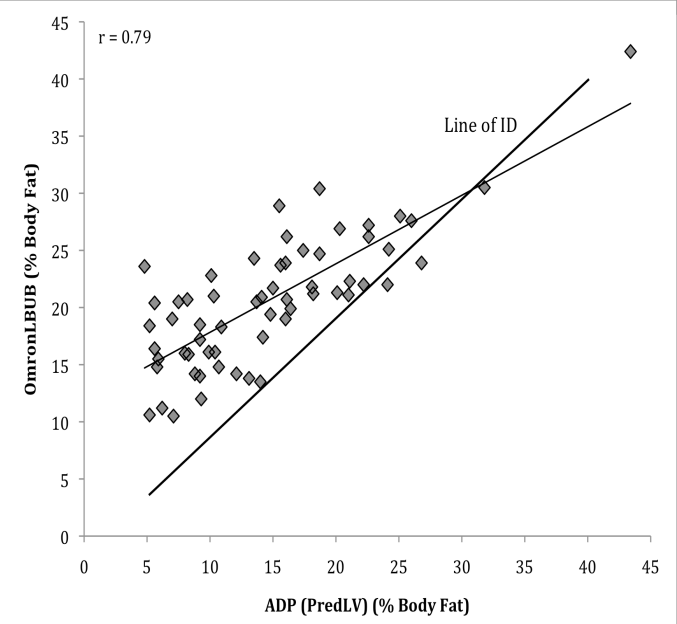

c.

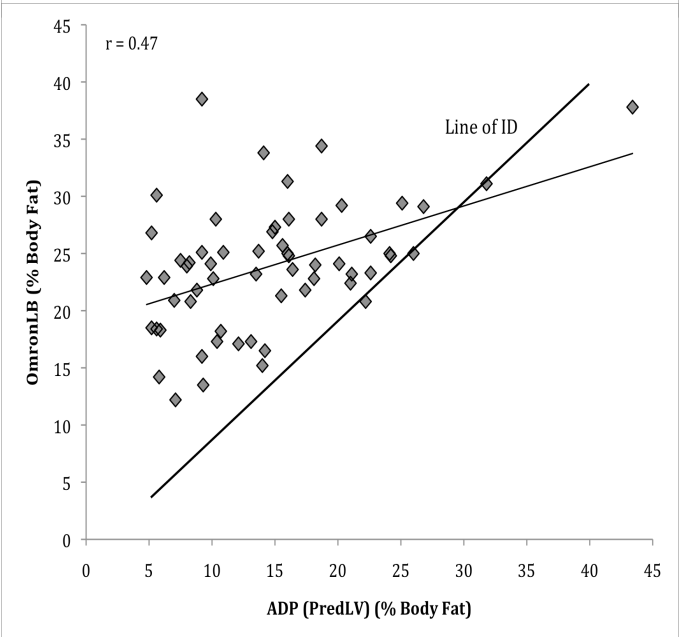


FIGURE 3. Correlation and Regression Analyses of Body Composition Techniques Significantly Different from Criterion Reference (ADP) for Females.

a.

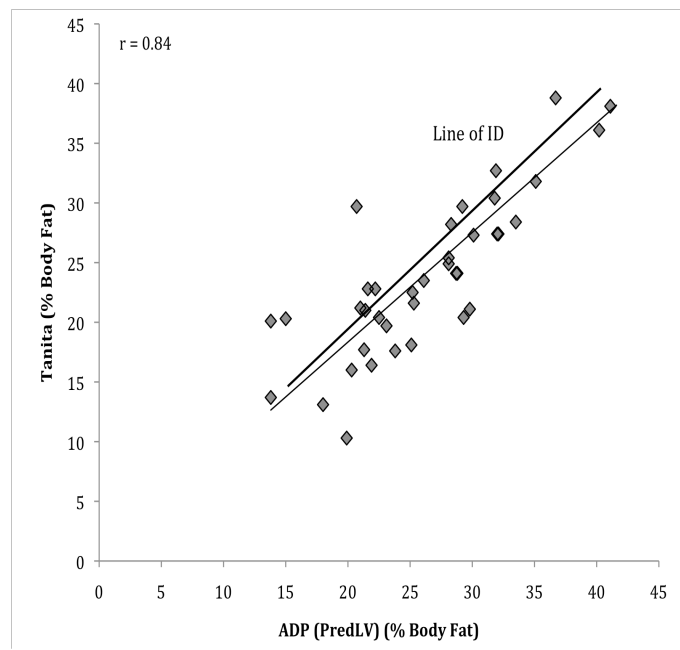

b.

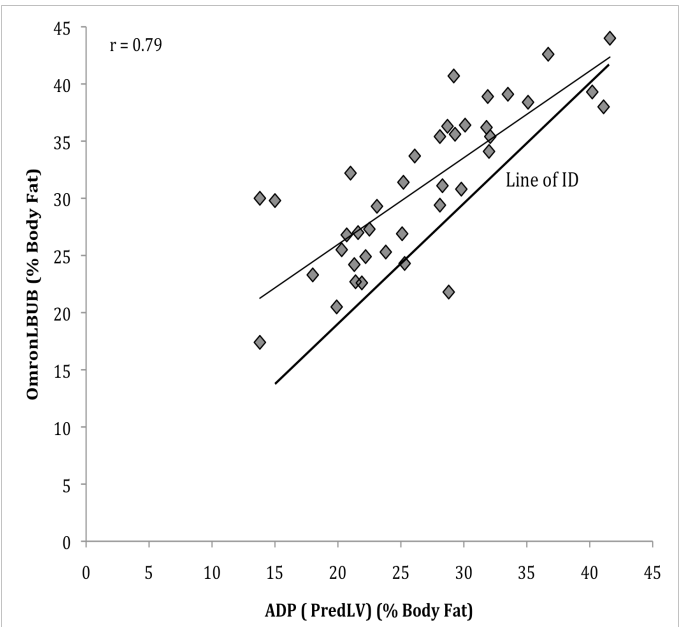

c.

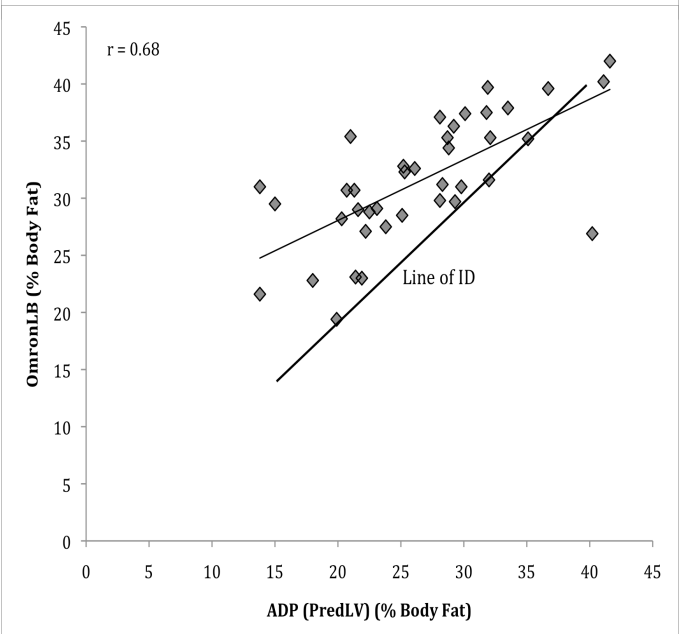




\section{CHAPTER II}

\section{EXTENDED LITERATURE REVIEW}

\section{Introduction}

According to the Centers of Disease control, nearly 64\% of Americans are classified as overweight or obese (5). The ability to accurately measure body fat is critical because of the established association of excess body fat and a variety of diseases such as diabetes mellitus, hypertension, cardiovascular disease, and hyperlipidemia (2,17,20,22). Many researchers contemplate the use of Body Mass Index (BMI) as a means of assessing overweight and obesity levels in the general population due to its feasibility. An individual's BMI is the product of their mass in kilograms $(\mathrm{kg})$ divided by height in meters squared $\left(\mathrm{m}^{2}\right)$.

BMI relies on cut off levels based on associations with mortality and morbidity in large population surveys that have been recommended as guidelines to determine healthy, desirable weights. Research has indicated that BMI may be a useful tool in assessing the general population $(13,15)$. However, other research has demonstrated the need for more measures other than BMI when assessing individuals, especially athletes whose sport requires them to be larger $(4,17)$. The BMI has been criticized because the weight does not differentiate between fat, muscle, bone, water, or vital organs $(4,17$.) Therefore, an individual with high fat-free mass (FFM) relative to stature may have a BMI value but 
not be obese (25).

Given the questions surrounding BMI, the need for body composition assessment technology has been in high demand. In the past, there were relatively few options available for the measurement of body composition such as bioelectrical impedance, hydrostatic weighing, air displacement plethysmography, and DXA (1-4,6-25). Most of the older technologies were expensive, lacked, portability, and required expertise to operate. These older technologies are still considered the criterion methods of assessing body composition. Inconveniently, UWW and ADP are not readily available to the general population. UWW requires the use of technical expertise to ensure the validity of each test. UWW involves repeated submersion with a maximal exhalation and can lead to client discomfort $(2,10,24)$. The ADP utilizing the BOD POD ${ }^{\circledR}$ can be viewed as advantageous due to the fact that it requires less technical skill than UWW and uses air instead of water to calculate body density which provides the subject with a more comfortable testing environment $(2,8-10,16,17,19,24)$. Some studies indicate that there is no significant difference between ADP and UWW $(2,9)$ whereas other studies indicate there is a difference between the two methodologies (24).

With the increasing demand to assess body composition, recent technological advances have resulted in a wide variety of types, models, and brands of body composition analyzers $(1,2,7,11,18-20,22,24)$. A variety of consumer grade devices targeted at the public claim to estimate $\% \mathrm{BF}$ accurately through bioelectrical impedance. There are numerous studies investigating body composition techniques that are available to consumers and it has recently been questioned whether the consumer grade devices 
utilizing bioelectrical impedance analysis (BIA) may be accurately used for determining body composition $(1,2,8,12,18-20,23)$.

\section{Body Fat Analysis}

The body is composed of water, protein, minerals, and adipose tissue. Excess adipose tissue (obesity) has been shown to be detrimental to human health and has been linked to multiple medical conditions such as diabetes, heart disease, and several types of cancer $(1,6,9,25)$. Maintaining a healthy percentage of body fat is essential in minimizing the occurrence of negative conditions (20). While adipose tissue has been associated with deleterious health outcomes, preserved lean mass is positively associated with physical fitness, higher caloric expenditure and exercise capacity, all of which are associated with a better survival (25). Body composition can be measured in a variety of ways. Two-component models separate body composition into two components: fat mass (FM) and fat free mass (FFM) (24-25). Fat-Free Mass assumes that water, bone, and muscle are all the same density (9). Commonly, the two-component model involves measuring $\mathrm{Db}$ and then using a conversion formula to estimate relative body fat $(\% \mathrm{BF})$ (24). The assessment of fat mass and fat-free mass provides valuable information about the physical and metabolic statuses of humans (25). In addition, the ability to accurately measure body fat is important because of the established association between high amounts of body fat and a variety of disease processes such as hypertension, diabetes mellitus, coronary artery disease, and hyperlipidemia (2). Multi-component model, combining body density (Db), total body water (TBW), and today body mineral data are frequently used to derive criterion measures of body composition $(19,24)$. 


\section{Body Fat Assessment Techniques}

Body Mass index (BMI) is the most widely used measure to diagnose obesity (17, 21). Since methods for the direct measurement of body fat are time-consuming and expensive, their application is limited to research settings and applied to small samples (25). Weight and stature can be measured easily in large samples with high precision (25). BMI is calculated using total body mass, it contains two factors that have opposite biological effects, adipose tissue and lean mass (21). BMI is the result of the individual's weight in kilograms $(\mathrm{kg})$ divided by meters, squared $\left(\mathrm{m}^{2}\right)$. Once BMI is calculated, it is established through classifications as a surrogate measure for relative body fatness (17). A BMI measure of $25-29.9 \mathrm{~kg} \mathrm{~m}^{2}$ is considered overweight and a BMI greater than 30 $\mathrm{kg} \mathrm{m}^{2}$ is considered obese (17). Therefore, adults with a BMI greater than $25 \mathrm{kgm}^{2}$ are considered to have excess $\mathrm{BF} \%$ and are considered to be at risk for developing hypertension, high cholesterol, diabetes, and coronary artery disease. $(6,17)$.

Bioelectrical Impedance (BIA) is a method that is easy to use, inexpensive and readily available that has broad application in research laboratories, hospitals, private clinics, and health centers $(6,18,19)$ The technology has been in use for over 100 years, but BIA for estimating body composition was only introduced in the 1980's $(19,23)$. Bioelectrical Impedance estimates body resistance, or impedance, from a voltage drop initiated from a small current passed between electrodes (2). It is dependent on three variables: the length of the conductive path, the volume of the conductive material, and the resistivity of the conductive material (18). The level of impedance, an indication of the water and electrolyte composition of the body, is used to estimate lean tissue content 
and body water volume from developed regression equations $(2,18)$. Instruments using BIA can provide valid estimates of total body water (TBW) and fat free mass (FFM) and thus can estimate percent body fat (\%BF) (19). Assuming a hydration fraction of lean tissue, usually $73 \%$, and an assumption of a constant hydration of lean mass, additional regression equations are used to estimate lean body mass and fat mass $(2,3,18)$. The impedance value is used in an equation chosen by the manufacturer to determine body density and $\% \mathrm{BF}(19)$. The equations are specific to the group on which they were established $(18,19)$. When the appropriate BIA equation is used the standard error of the estimate is approximately $3-5 \%$ body fat (23).

Air-displacement plethysmography (ADP) was not developed into a viable system for routine use until the mid-1990s (8). The only commercially available system for airdisplacement plethysmography is known by the trade name BODPOD ${ }^{(8)}$. The BODPOD ${ }^{\circledR}$ is a faster, more convenient, and easier test to administer. The BODPOD ${ }^{\circledR}$ utilizes ADP to determine body volume by measuring the reduction in chamber volume caused by introduction of a subject into a chamber with a fixed air volume $(2,24)$. The BODPOD ${ }^{\circledR}$ uses a pressure-volume relationship to derive body volume for a subject seated inside the chamber using Boyle's Law — at a constant temperature, volume and pressure are inversely related. $(8,10,24)$. The body density is equal to the volume of air in an empty chamber minus the volume of air remaining in the chamber $(8,24)$. After wholebody density is therefore determined and body composition is calculated by using previously validated prediction equations $(2,24)$. Before each test, the BODPOD $\AA$ is calibrated to the manufacturer's instructions using a cylinder of known volume (50 L) 
$(9,10,16,24)$. For the measurement of ADP, participants are asked to change into a tightfitting swimsuit or spandex and to remove all jewelry $(2,24)$. Participants wear a tightfitting swim cap during the assessment to minimize the effect of hair on body volume assessment. Body mass is first measured on a calibrated electronic scale. The subject then sits in the air-displacement plethysmograph for body volume measurement. Participants are instructed to sit quietly with an erect posture and normal respiration with hands folded on their laps and feet on the floor of the device $(2,24)$. A minimum of two 50 -second tests is conducted to ensure reliability of measures. The body volume measurement is repeated if the two measurements are not within $150 \mathrm{~mL}$ of each other $(2,9,10,16,24)$. BODPOD ${ }^{\circledR}$ uses a two-component model assuming fat free mass- protein, water, and bone are equal densities.

Hydrodensitometry or underwater weighing (UWW) was considered to be the gold standard of all densitometric methods $(2,9,10)$. UWW uses the Archimedes principle — a body immersed in a fluid is buoyed by a force equal to the weight of the displaced fluid — to determine total body volume by measuring the difference between a participants weight in water and that in air and thus determining whole-body density $(2,10)$. This technique requires the subject to be completely submerged underwater while exhaling maximally (yielding residual lung volume) to minimize the effect of buoyancy from lung air $(2,9,10)$. Participants sit in a chair that is submerged in a water tank and attached to multiple electronic load cells. After a maximal exhalation, a computerintegrated scale reading is obtained (2). Body volume is calculated according to the Archimedes principle, with correction for residual lung volume $(10,25)$. This volume 
value is used to compute whole-body density and the density value is entered into the population specific equation. UWW is can be time constraining, labor intensive, and cause subject discomfort $(2,9,10,24)$. Similar to ADP, UWW uses a two-component model assuming fat free mass - protein, water, and bone - are equal densities.

\section{Body Fat Assessment Techniques Ability to Assess Body Fat Percentage}

\section{Body Mass Index}

Ode, Pivarnik, Reeves, and Knous (2007) sought to describe the relationship between BMI and percent fat as well as determine the accuracy of BMI as a predictive measurement of percent fat in college athletes and non-athletes (17). The participants recruited were 226 varsity athletes and 213 non-athletes from a university. The varsity athletes were drawn from a variety of sports including football, basketball, hockey, wrestling, crew, and softball. The non-athletes were kinesiology majors enrolled in an exercise physiology laboratory class (17).

BMI was calculated using body mass in kilograms divided by height in meters squared. Air displacement plethysmography was performed using the BOD POD to measure the body volume of the participants. From this measurement, body density was calculated and converted to body fat percentage utilizing the Siri equation (17). A BMI between 25 and $30 \mathrm{~kg} / \mathrm{m}^{2}$ was categorized overweight and a BMI of $30 \mathrm{~kg} / \mathrm{m}^{2}$ or greater was categorized as obese. Over-fat was classified as a body fat percentage greater than or equal to $20 \%$ in men and $33 \%$ in women (17).

Using the results from the BMI and air displacement plethysmography, participants were categorized as overweight and over-fat (true positive), overweight and 
normal fat (false positive), normal weight and over-fat (false negative), and normal weight and normal fat (true negative). Ode et al. (2007) found that the male athlete group was significantly heavier, taller, and had a lower body fat percentage than the non-athlete group. Linemen in the study were found to be significantly heavier, taller, and had a greater BMI and percent fat than both the male athletes and non-athletes. The female athletes also had significantly greater height, body mass, and BMI than the female nonathletes (17).

The percentage of participants who fell into the false positive and false negative groups was utilized to assess the accuracy of BMI in determining body fat percentage (17). Ode et al. (2007) found that $67 \%$ of all male athletes, and $25 \%$ of male non-athletes, were false positives. In the female participants, $31 \%$ of the athletes and $7 \%$ of the nonathletes were considered false positives. None of the male or female athletes were categorized as false negatives, and only a small percentage of over-fat male non-athletes were considered false negatives (17).

Using the data from the testing results, Ode et al. (2007) calculated the BMI values at which athletes would be probable to have body fat percentages indicating overfatness. The BMI cutoff in male athletes was established to be $27.9 \mathrm{~kg} / \mathrm{m}^{2}$, linemen were given their own BMI cutoff value of $34.1 \mathrm{~kg} / \mathrm{m}^{2}$, and the value for female athletes was found to be $27.7 \mathrm{~kg} / \mathrm{m}^{2}$ (17). For collegiate non-athletes, males were given a BMI cutoff value of $26.5 \mathrm{~kg} / \mathrm{m}^{2}$ and female non-athletes were given a value of $24.0 \mathrm{~kg} / \mathrm{m}^{2}$ (17).

Ode et al. (2007) concluded that BMI is not an accurate measure of fatness in collegiate athletes and non-athletes; BMI misclassifies normal fat individuals a large 
percentage of the time (17). The findings of this study are constant with previous research that BMI will overestimate body fat percentage in an athletic population. However, this is one of the first studies to offer a predictive BMI value for male and female athletes. The BMI cutoff values that Ode et al. (2007) proposed for male and female collegiate athletes, as well as male collegiate non-athletes, should be investigated in other athlete populations. Ode et al. (2007) recognized that their sample is a convenience sample and therefore may lack external validity. Since the non-athlete population recruited for this study consisted of Kinesiology majors, it is possible that this sample is more physically active than the general population. Therefore, the data collected on the non-athlete population should be interpreted cautiously (17).

Kraemer, Torine, Silvestre, French, Ratamess, Spiering, Hatfield, Vingren, and Volek (2005) examined the differences among positions in body size and percent body fat in NFL athletes prior to the start of the regular season. Previous investigations have indicated that body fat is highly associated with the position of football players. Due to improvements in strength and conditioning programs, most of the research populace believes the players in the NFL are larger than players in previous seasons. Although research has shown this to be true for collegiate football players, Kraemer et al. (2005) investigated the case for NFL players.

Fifty-three members of the Indianapolis Colts were measured for BMI and body fat percentage. BMI was assessed using a calibrated scale to measure weight, in kilograms, divided by height, in meters, squared. A body fat percentage was calculated for each player using air-displacement plethysmography in a BOD POD. Testing was 
performed during the summer training camp prior to the 2003 football season. Kraemer et al. (2005) believed that the athletes would be in top condition at this point following their off-season conditioning programs.

No significant differences were found between offensive linemen, defensive linemen, quarterbacks, kickers, or tight ends, all of which were significantly taller than linebackers, running backs, wide receivers, and defensive backs. In terms of body mass, there were no significant differences between offensive and defensive linemen, both of whom were significantly heavier than the rest of the positions. Offensive linemen were found to have the highest body fat percentage followed by defensive linemen. Once these results were compared to previous investigations, Kraemer et al. (2005) found that the largest increases in body mass compared to the 1970's has occurred in offensive and defensive linemen. Kraemer et al. (2005) noted that height has remained almost unchanged for more than 30 years, with the exception of defensive backs. However, the Colts offensive and defensive line players in this study were found to have lower body fat percentages than a similar study on the 1998 Falcons. This reduced body fat percentage could be due to different conditioning programs or nutritional interventions. It could be due to varying offensive styles that call for a different type and size of athlete. Linebackers were also found to have become leaner, a phenomenon which authors attribute to changes in the game of football, such as an emphasis on the passing game or changes in coverage responsibilities.

An analysis of BMI values categorizes athletes in every position in this study as overweight or obese. However, when body fat percentage is taken into consideration, 
most athletes are categorized to be healthy or in good health, making BMI classifications false positives (12). An exception to the reported false positives is the offensive linemen who had both high BMI recordings as well as high body fat percentages. Despite the high levels of body fat percentages, Kraemer et al. (2005) reported that the percentages were not as extreme as the BMI values would indicate.

Based on previous investigations, Kraemer et al. (2005) concluded that the body size of NFL players has remained similar over seasons. An exception to this is offensive and defensive linemen, who have demonstrated an increased body mass. However, with this increased body mass is a decrease in percentage body fat, meaning a greater increase in lean body mass has occurred. This study provides further evidence for the misclassification of athletes using BMI. With the exception of offensive linemen, the athletes labeled as overweight or obese according to BMI standards were considered to be healthy when compared to air-displacement plethysmography results. Although the offensive linemen were not considered healthy by body fat percentage standards, the extent to which they were overweight or obese was not as extreme as was reported by the BMI value.

Other research literature has shown BMI does not accurately reflect body fat percentage and tends to overestimate or underestimate body fatness (21). Ode et al. (2007) constructed a study in which collegiate athletes and non-athletes are measured with BMI and air displacement plethysmography. Results were consistent with previous findings that Body Mass Index has a tendency to over-predict overweight and obesity levels. When examining BMI in athletes, Kraemer et al. (2005) found that NFL players' 
BMI values demonstrated many false positives when compared to players' body fat percentages. However, suggestions of adjusted BMI cutoff values for male and female athletes that would better correlate with body fat percentage should be created and used in this population. These adjusted BMI values warrant further research to determine generalizability to the athletic population.

\section{Bioelectrical Impedance Analysis}

A variety of consumer grade devices targeted at the public claim to estimate $\% \mathrm{BF}$ accurately through bioelectrical impedance. Practical and inexpensive measurement tools for body composition have been developed for consumers and have been used in measurements such as worksite heath risk assessments, epidemiological studies, commercial weight loss programs, and athletics. Bioelectrical impedance analyzers are inexpensive machines but have little research published about their validity or reliability. Therefore, studies must be conducted to determine its accuracy and reliability. Previous literature indicates a varying results emphasizing that numerous products have been claimed to be accurate in relation to established criterion references while other literature indicates the same products to not be accurate compared to established criterion references.

The Omron HBF-500 estimates \%BF by sending electrical currents through the hands via handheld electrodes and the feet via electrodes on the scale's surface. The combination of electrodes accounts for both upper body and lower body when estimating \%BF. The Omron HBF-500 has become a well-sought product by consumers for its acclaimed precision and accuracy. Pribyl, Smith, and Grimes (2011) developed a study to 
analyze the accuracy of the inexpensive consumer product designed to assess body composition in comparison to the BodPod® .

Forty-eight male and 33 female college students participated in the study. On the day of the assessment, participants were asked to avoid exercise and to not have eaten a heavy meal three hours prior to measurement (20). Participants were asked to relieve themselves and to change into skintight clothing as recommended by the manufacturer including a swimcap. Participants were instructed to remove any jewelry, glasses, and shoes. Participants had their height measured along with their waist circumference. Participants were first assessed on the Omron HBF-500 which involved entering the participant's age, height, and gender. Participants stood on the scale barefoot and grabbed the handle electrodes for roughly 10 seconds until the assessment was completed. The next assessment was ADP using the BODPOD ${ }^{\circledR}$ system. The system was calibrated to the manufacturer's guidelines. Weight was obtained from the calibrated scale included with the BODPOD ${ }^{\circledR}$. After weight was obtained, participants entered the BODPOD ${ }^{\circledR}$ for two body volume measurements. Participants were instructed to relax, limit their movement, and breathe normally (20).

The result of the study demonstrated that the Omron HBF-500 significantly overestimated $\% \mathrm{BF}$ to a greater degree in females compared to males (20). The results indicated that there was a greater degree of agreement between the two instruments in males than with females (20). This study remained consistent with previous literature indicating the Omron HBF-500 to overestimate \%BF between individuals.

Pribyl et al. (2011) did not control for factors such as body hair and menstruation. 
Previous literature indicates that body hair can impact \%BF readings (2). Pribyl et al. (2011) determined that body hair to cause overestimation by roughly one percent. The study also did not regulate female's menstruation cycle which Pribyl et al. (2011) believes could have led to the large overestimation of females. There are not many published studies that control for menstrual cycle and Pribyl et al. (2011) suggests future studies control for menstrual cycle and to take additional measures to ensure that participants follow pre-test instructions. Although the estimates produced by the two instruments differ significantly, Pribyl et al. (2011) suggests the use of the Omron HBF500 could be used to gain a general body composition for males. For females, the degree of overestimation is too high to give a general body composition status. In cases where an accurate measurement of $\% \mathrm{BF}$ is crucial, using a more established method than Omron is recommended (20).

Peterson, Repovich, and Parascand (2011) developed a study to investigate userfriendly, inexpensive bioelectrical impedance analyzers. The argument is that the various equations chosen by the manufacturer is not reliable in a range of populations because the equations are specific to the group on which they were established (19). The purpose of the study was to investigate the accuracy of body fat percentage from seven different BIA models and a seven-site skinfold anlaysis compared with air displacement plethysmography in females (19).

Participants were 82 white females between the ages of 19-67 years of age. All participants were healthy, not pregnant, and were requested to abstain from eating or drinking for two hours prior to data collection (19). Participants were requested to not 
participate in moderate or vigorous activity for 24 hours (19). All testing was completed in one day. Anthropometric measurements were taken including height and weight with the subject in minimal clothing and without shoes. Body composition was first assessed using the BIAT because the protocol requires the subject to lie supine for 10 minutes prior to measurement (19). The rest of the field methods were completed in counterbalanced order with ADP as the final test for everyone (19). All measurements were completed in a 30-minute timeframe.

Results indicated the seven-site skinfold analysis had the strongest correlation to air displacement plethysmography $(\mathrm{r}=0.862)$. The three measurement techniques (SKF, BIAT, and $\mathrm{HH}$ ) were not significantly different fromm the mean of ADP, however, all underestimated percent body fat. The various assessment techniques (FF, LL1, LL2, LL3s) significantly overestimated body fat while the LL3a underestimated percent body fat (19).

The investigation indicates the precision of these devices must be questioned and research in the female population similarly to Pribyl et al. (2011). The study supports previous results indicating that segmental BIA measures correlate well with a criterion method but under or overestimate the individual \%BF measures. Segmental BIA provides an acceptable significant correlation with criterion methodologies but may not be accurate enough to provide precise and reliable measurements. More research on the validity and reliability on consumer grade body composition assessment devices need to be conducted to ensure the effectiveness of the various products.

Biaggi, Vollman, Nies, Brener, Flakoll, Levenhagen, Sun, Larabulut, and Chen 
(1999) sought to compare the measurements of body fat percentages between ADP with two established techniques, UWW and BIA in a heterogeneous sample of healthy men and women. The sample comprised of 23 men and 24 women between the ages of 19-48. Participants were screened for health and were excluded from participating if they had a history of heart disease, chronic obstructive pulmonary disease, pregnancy, or afraid of submersion in water. Participants reported to the testing having a 12-hour fast, no consumption of alcohol 12 hours prior, no intensive exercise 12 hours prior, adequate hydration, and avoidance of excessive use of moisturizing lotions.

Prior to all testing, participants' height and weight was measured. All participants underwent each testing protocol. First, the subject underwent air displacement plethysmography corresponding to the manufacturers protocol utilizing the BODPOD®. Secondly, the participants underwent bioelectrical impedance analysis with the Biodyamics model 310. Two signaling electrodes were placed on he dorsal surface of the right foot at the space between the metatarso-phalagneal joints of the great and second toes, as well as on the dorsal right hand at the space between the metacarpo-phalangeal joints of the second and third digits (2). The two detecting electrodes were placed between the styloid processes of the right radius and ulna and between the medial and lateral malleoli of the right ankle. The measurement was taken with the subects in a supine position with hands and feet slightly adducted from the midline (2). Body fat percentage was calculated using an unpublished regression equation of the impedance measurements and \%BF. Lastly, the participants underwent hydrostatic weighing. Once follow immersed in the tank, the participants were instructed to exhale maximally and the 
computer-integrated scale reading was obtained after the subject signaled for the end of maximal exhalation. This procedure was repeated until 2 measures of weight agreed to \pm 50g. Body volume was calculated according to the Archemides principle, with correction for residual lung volume. This volume was used to compute whole-body density and the density value was entered into the equation of either Siri or Shutte for estimation of $\% \mathrm{BF}$.

The results of the study show that the $\% \mathrm{BF}$ achieved from ADP was not significantly different from derived from HW or BIA and was significantly correlated with both. There was a significant sex effect where AP underestimated the $\% \mathrm{BF}$ in men and overestimated $\% \mathrm{BF}$ in women. The reasoning for the significant sex effect is due to body hair negatively influencing the body volume measurement.

The general findings of the study show that ADP is a valid method of body composition assessment. The study indicated that ADP is an accurate measurement of body fat when compared to the gold standard of HW (2). Correlating with previous literature, BIA can be accurate when used for group estimation; however, the wide variations in $\% \mathrm{BF}$ could be limiting terms in the assessment techniques accuracy and may not be accurate for all individuals. ADP can be used in place of HW due to its accuracy and non-limitations to special populations (2).

\section{Densitometry}

Traditionally, two compartment models such as densitometry and hydrometry have been commonly utilized as reference methods for body composition (10). Underwater weighing and air-displacement plethysmography have been evaluated throughout many research studies. The investigations of the studies have varying results, however, both have been considered interchangeable gold standards. 
Ginde, Geliebter, Rubiano, Silva, Wang, Heshka, and Heymsfield (2005) investigated air-displacement plethysmography and underwater weighing in normal weight to severly obese participants. Although underwater weighing is recognized as a gold standard in the scientific community, not all clients are able to participate in the technical procedure. Therefore, it is important to validate ADP and UWW to ensure their accuracy with the overweight and obese population. The purpose of this study was to compare the body density measured by ADP to the body density measured by UWW in the participants who are overweight and obese.

There were 123 participants all over the age of 18 years. Participants reported no diagnosed illnesses. Participants were instructed to fast overnight before body composition studies. Participants were assessed with both measurement techniques on the same day. Height and weight was assessed and body mass index was calculated. Participants participated in air displacement plethysmography via the BODPOD ${ }^{\circledR}$ following the manufacturer's instructions. (10) Following the ADP assessment, participants participated in 5-10 trials of underwater weighing (10).

Of the 123 participants, 15 were overweight, 70 were obese, and 10 were severely obese (10). The mean values for UWW and ADP did not different significantly for the whole subject group and the two measures were highly correlated $(\mathrm{r}=0.94)$. There were no significant differences in body density by UWW and ADP for the subgroup of normal weight and the severely obese. There were no systematic differences among the four subgroups. The results indicate no significant difference between UWW and ADP in the group mean percent fat estimate. Furthermore, ADP compared with UWW as the 
reference revealed no significant bias for the estimation of percent fat (10).

The results of this study indicate strong validity of the BODPOD density estimates in overweight and obese participants. Unlike previous literature, Ginde et al. (2005) did not control for the necessary pre-test instructions except for fasting. This could be due to notion that the target population is predominately sedentary. However, this is an important finding because of the technicality and the discomfort that is brought about from the UWW technique. It is important because the feasibility of ADP will allow people of all potential disabilities for underwater weighing to receive an accurate body composition assessment. Furthermore, it is a faster, more convenient, and easier test to administer, thereby reducing potential error associated with technician skill.

Wagner, Heyward, and Gibson (2000) had a similar study to that of Ginde et al. (2005). Further investigating air-displacement plethysmography and underwater weighing, Wagner et al. (2000) evaluated the validity of these assessment tools in a heterogeneous African American population. With the obesity epidemic, it is critical to obtain valid and reliable estimates of body density and \%BF. The purpose of this study was to cross validate body density measures obtained by the BODPOD with to that obtained from UWW.

Thirty African American men, ages 19-45 years old, volunteered to participate in this study. The subject pool was heterogeneous with respect to age, height, body mass, body fatness, physical activity level, and socioeconomic status. All participants underwent a physical examination by a physician and were deemed to be in good health (24). Participants stayed overnight in the clinical research ward of a hospital to control 
for the influence of physical activity and food and drug intake on body composition measures. Weight was assessed via the calibrated electronic scale of the BODPOD and height was assessed with a standard stadiometer. Participants underwent DXA, BODPOD, and UWW following manufacturer instructions of each assessment.

The body density from the BODPOD and UWW were highly correlated $(\mathrm{r}=0.91)$. Although the mean difference in body density between UWW and ADP was only $.000450 \mathrm{~g} \mathrm{cc}^{-1}$, the paired t-test revealed that the body density from ADP was significantly less than the density of UWW (24). The Schutte and Wagner conversion formulas produced significantly different estimates of $\% \mathrm{BF}$. The significant differences were seen regardless of which formula was used to convert body density to \% $\mathrm{BF}$ (24). Furthermore, the average \%BF obtained from UWW did not differ significantly from DXA. The body densities obtained from the BODPOD were underestimated by a small, but significant amount (24).

Wagner et al. (2000) exhibit more control over their participants than the previous study to ensure pre-testing protocols were met. That prevents subject reliability to ensure the recommendations were met. Although this particular study is from 2000, it only further exemplifies that more studies need to be conducted to ensure that newer equipment and technological advances maintain the accuracy of criterion references. The BODPOD is easy to use, requires little effort on the subject, and is quick and convenient method of estimating $\mathrm{Db}$ and $\% \mathrm{BF}$, it is slowly replacing the UWW method (24). Although measurements from ADP and UWW were statistically different, the difference was a very small amount. 


\section{Summary}

The general findings of the previous literature show that ADP is a valid method of body composition assessment. It is consistently being demonstrated that BMI needs to be discontinued as a measurement of adiposity since it only takes stature and mass into the equation and does not provide adequate information about body composition. BMI can be a good diagnostic tool for the general population but should be followed up with an assessment to determine if the BMI reading is entirely accurate to the individual in regards to adiposity. The studies indicated that ADP is an accurate measurement of body fat when compared to the criterion reference of HW. Correlating with previous literature, BIA can be accurate when used for group estimation; however, the wide variations in $\% \mathrm{BF}$ could be limiting terms in the assessment techniques accuracy and may not be accurate for all individuals. Furthermore, consumer-grade BIA techniques can be used for males to assess changes in body composition overtime, but should be avoided with the female population due to its overestimation. ADP can be used in place of HW due to its accuracy and non-limitations to special populations; however, it should be made aware that UWW is still an accurate means of body composition assessment. . Gately et al. (2003) indicates that it is important to identify a method that will undoubtedly be its ability to accurately assess longitudinal changes in body composition. More investigation needs to be completed assessing the validity and accuracy of all body composition techniques and to re-evaluate criterion references. 


\section{References}

1. Beam, J. R., \& Szymanski, D. J. (2010). Validity of 2 Skinfold Calipers in Estimating Percent Body Fat of College-Aged Men and Women. Journal of Strength, 24(12), 3448-3456. doi:10.1519/JSC.0b013e3181bde1fe

2. Biaggi, R. R., Vollman, M. W., Nies, M. A., Brener, C. E., Flakoll, P. J., Levenhagen, D. K., Sun, M., Karabulut, Z., \& Chen, K. Y. (1999). Comparison of airdisplacement plethysmography with hydrostatic weighing and bioelectrical impedance analysis for the assessment of body composition in healthy adults. The American journal of clinical nutrition, 69(5), 898-903.

3. Bosy-Westphal, A., Later, W., Hitze, B., Sato, T., Kossel, E., Gluer, C.-C., Heller, M., \& Muller, M. J. (2008). Accuracy of bioelectrical impedance consumer devices for measurement of body composition in comparison to whole body magnetic resonance imaging and dual X-ray absorptiometry. Obesity facts, 1(6), 319-324. doi:10.1159/000176061

4. Buell, J.L., Calland, D., Hanks, F., Johnston, B., Pester, B., Sweeney, R., Thorne, R. (2008). Presence of Metabolic Syndrome in Football Linemen. Journal of Athletic Training, 43(6), 608-616.

5. Center for Disease Control [Internet]. Atlanta, GA. Healthy People 2010: Focus on Area 12 Heart Disease and Stroke. Available from http://www.cdc.gov/dhdsp/library/hp2030/objectives.

6. Dehghan, M., \& Merchant, A. T. (2008). Is bioelectrical impedance accurate for use in large epidemiological studies? Nutrition Journal, 7(1), 26. doi:10.1186/14752891-7-26

7. Demura, S., Sato, S., \& Kitabayashi, T. (2004). Percentage of Total Body Fat as Estimated by Three Automatic Bioelectrical Impedance Analyzers. Journal of Physiological Anthropology and Applied Human Science, 23(3), 93-99.

8. Fields, D. A., Goran, M. I., \& McCrory, M. A. (2002). Body-composition assessment via air-displacement plethysmography in adults and children: a review. The American Journal of Clinical Nutrition, 75(3), 453-467.

9. Gately, P. J., Radley, D., Cooke, C. B., Carroll, S., Oldroyd, B., Truscott, J. G., Coward, W.A., \& Wright, A. (2003). Comparison of body composition methods in overweight and obese children. Journal of Applied Physiology, 95(5), 20392046. doi:10.1152/japplphysiol.00377.2003 
10. Ginde, S. R., Geliebter, A., Rubiano, F., Silva, A. M., Wang, J., Heshka, S., \& Heymsfield, S. B. (2005). Air displacement plethysmography: validation in overweight and obese participants. Obesity research, 13(7), 1232-1237. doi:10.1038/oby.2005.146

11. Jensky-Squires, N. E., Dieli-Conwright, C. M., Rossuello, A., Erceg, D. N., McCauley, S., \& Schroeder, E. T. (2008). Validity and reliability of body composition analyzers in children and adults. British Journal of Nutrition, 100(04), 859-865. doi:10.1017/S0007114508925460

12. Kraemer, W.J., Torine, J.C., Slvestre, R., French, D.N., Ratamess, N.A., Spiering, B.A., Hatfield, D.L., Vingren, J.L., Volek, J.S. (2005). Body Size and Composition of National Football League Players. Journal of Strength and Conditioning Research, 19(3), 485-489.

13. Laurson, K.R., Eisenmann, J.C. (2007). Prevalence of Overweight Among High School Football Linemen. JAMA, 297(4), 363-364.

14. Loenneke, J. P., Wilson, J. M., Wray, M. E., Barnes, J. T., Kearney, M. L., \& Pujol, T. J. (2012). The Estimation of the Fat Free Mass Index in Athletes. Asian Journal of Sports Medicine, 3(3), 200-203.

15. Malina, R.M., Morano, P.J., Barron, M., Miller, J.S., Cumming, S.P., Kontos, A.P., Little, B.B. (2007). Overweight and Obesity among Youth Participants in American Football. The Journal of Pediatrics, 151, 378-382.

16. Noreen, E. E., \& Lemon, P. W. (2006). Reliability of air displacement plethysmography in a large, heterogeneous sample. Medicine and science in sports and exercise, 38(8), 1505.

17. Ode, J. J., Pivarnik, J. M., Reeves, M. J., \& Knous, J. L. (2007). Body mass index as a predictor of percent fat in college athletes and nonathletes. Medicine and science in sports and exercise, 39(3), 403.

18. Pateyjohns, I. R., Brinkworth, G. D., Buckley, J. D., Noakes, M., \& Clifton, P. M. (2006). Comparison of Three Bioelectrical Impedance Methods with DXA in Overweight and Obese Men. Obesity, 14(11), 2064-2070. doi:10.1038/oby.2006.241

19. Peterson, J., Repovich, W., \& Parascand, C. (2011). Accuracy of Consumer Grade Bioelectrical Impedance Analysis Devices Compared to Air Displacement Plethysmography. International Journal of Exercise Science, 4(3). Retrieved from http://digitalcommons.wku.edu/ijes/vol4/iss3/2 
20. Pribyl, M., Smith, J., \& Grimes, G. (2011). Accuracy of the Omron HBF-500 Body Composition Monitor in Male and Female College Students. International Journal of Exercise Science, 4(2). Retrieved from http://digitalcommons.wku.edu/ijes/vol4/iss2/2

21. Romero-Corral, A., Somers, V. K., Sierra-Johnson, J., Thomas, R. J., Bailey, K. R., Collazo-Clavell, M. L., Allison, T.G., Korinek, J., Batsis, J.A., \& Lopez-Jimenez, F. (2008). Accuracy of Body Mass Index to Diagnose Obesity In the US Adult Population. International journal of obesity (2005), 32(6), 959-966. doi:10.1038/ijo.2008.11

22. Steinberger, J., Jacobs, D. R., Raatz, S., Moran, A., Hong, C.-P., \& Sinaiko, A. R. (2005). Comparison of body fatness measurements by BMI and skinfolds vs dual energy X-ray absorptiometry and their relation to cardiovascular risk factors in adolescents. International journal of obesity (2005), 29(11), 1346-1352. doi:10.1038/sj.ijo.0803026

23. Utter, A.C., Scott, J.R., Oppliger, R.A., Visich, P.S., Goss, F.L., Marks, B.1, Nieman, D.C., \& Smith, B.W. (2001). A comparison of leg-to-leg bioelectrical impedance and skinfolds in assessing body fat in collegiate wrestlers. Journal of strength and conditioning research / National Strength \& Conditioning Association, 15(2), $157-160$.

24. Wagner, D. R., Heyward, V. H., \& Gibson, A. L. (2000). Validation of air displacement plethysmography for assessing body composition. Medicine and science in sports and exercise, 32(7), 1339-1344.

25. Wellens, R. I., Roche, A. F., Khamis, H. J., Jackson, A. S., Pollock, M. L., \& Siervogel, R. M. (1996). Relationships Between the Body Mass Index and Body Composition. Obesity Research, 4(1), 35-44. doi:10.1002/j.15508528.1996.tb00510.x 